\title{
As Máculas da Ditadura Militar Brasileira
}

The stains of the Brazilian Military Dictatorship

Maria Cristina Ferreira dos Santos*

ymaria1@hotmail.com

Resumo: O objetivo do artigo é analisar, sob o viés mnemônico, histórico e traumático, a obra autobiográfica Mácula, de Pedro Penteado do Prado (2013), a qual discorre sobre as mazelas de um garoto que injustamente foi acusado de subversivo e sofreu escabrosas torturas. Ademais, demonstrar que o sofrimento dos que foram massacrados pela falta de liberdade que pairou no Brasil durante o período Militar não apenas os determinou como sujeitos históricos que tem memórias enfermas, mas também nos determina como herdeiros destes anos de chumbo. Para isso, serão usados os pressupostos teóricos de Martin Heidegger, Jean Paul Sartre, Jan Assmann e Paul Ricoeur.

Palavras-chave: Ditadura Militar, trauma, memória

Abstract: The aim of this paper is to analyze, under the mnemonic, historical and traumatic bias, the autobiographical work Macula, of Pedro Prado Penteado (2013), which discusses the wounds of a kid who unfairly accused of subversive and suffered rugged torture. Moreover, to show that the suffering of those who were massacred by the lack of freedom that hung in Brazil during the military period not only determined as historical subjects that have ill memories, but also determines us as heirs of the years of lead. For this, they will use the theoretical assumptions of Martin Heidegger, Jean Paul Sartre, Jan Assmann and Paul Ricoeur.

Keywords: Military Dictatorship, trauma, memory 


\section{Introdução}

No romance autobiográfico Mácula (2013), Pedro Penteado do Prado reconstrói sua experiência com a repressão da Ditadura Militar Brasileira, em discurso indireto livre e tempo psicológico, ou seja, rememorações de diferentes instantes se imbricam para formar seu enredo comovente e incisivo.

Entrementes está dependurado injustamente em um cabide, o garoto, o qual adrede tem seu nome oculto na narrativa, para mostrar como o sistema repressivo logrou anular identidades, relembra distintos fatos de diferentes momentos para manter-se acordado e, dessa forma, vivo. O menino narrador insere o leitor num amontoado de questionamentos acerca da noção de trauma, memória, esquecimento, violência e arte engajada enquanto ele mesmo tenta entender o contexto histórico que está vivendo e os motivos de ter seu jovem corpo maltratado por algozes que se diziam amigos $d a$ nação.

Podemos observar suas indagações abaixo:

O garoto estava expiando pecados os quais não sabia tê-los cometido. Os soldados que o dependuraram naquele cabide tão estranho, se omitiram de falar os motivos a não ser de classificá-lo como "comunista sujo" e de outros adjetivos pejorativos, no seu linguajar estranho, cifrado. A mente do garoto trabalhava de forma vertiginosa, lembrando de tantos fatos que sua curta vida de menino lhe proporcionara até aqueles dias de chumbo, quando então se insurgia uma "revolução" com cara de ditadura militar que tomara o poder e punha em cheque a democracia brasileira (PRADO, 2013, p. 14).

A personagem principal, que é denominada ora de garoto, ora de piá, ora de garçom, e nunca por seu nome, era um humilde adolescente de uma cidade interiorana de Santa Catarina que, para ajudar no sustento de sua família, necessitou largar os estudos e trabalhar como atendente de bar em Curitibanos. O Tropicana's Bar, nome do estabelecimento em que o jovem passava boa parte de sua semana, era ponto de encontro de onze subversivos, os quais formavam o Grupo dos 11, aquele que, segundo Leonel Brizola, deveria haver em cada cidade e se reunir para confabular contra o regime de opressão. A partir de outubro de 1963, sob o comando de Leonel de Moura Brizola, surge no Brasil o movimento denominado Grupo dos onze, "grupo de onze companheiros", objetivando incrementar as reformas prementes que o país tanto necessitava, bem como o rompimento contra o imperialismo americano e o especulativo capital estrangeiro.

O Grupo dos Onze de Curitibanos era formado por Adamastor, dono de um restaurante; Nego Dida, que não tinha emprego fixo; Acácio Louco, um sindicalista; Adilson, radialista; Romildo, um alfaiate; José Garbin, um contabilista; Valter Costenaro, sujeito que estudara em cidade grande, Adelmo, um militar que não aceitava o regime imposto; Negra Tita, uma prostituta; e Jorge Lacerda, o cabeça do grupo.

O pobre garoto, de apenas quinze anos, sequer compreendia o que se passava em seu local de trabalho, ouvia uma conversa ou outra, indagava os clientes assíduos do bar sobre vocábulos que escutava, e, após uma conversa com um dos integrantes do Grupo dos Onze, conclui:

Enquanto preparava a bebida, percebeu que ele, aquele garoto que já fora cultivador de hortaliças no quintal de sua mãe, desde os nove anos de idade fora sapateiro junto de seu pai; já fora engraxate, pipoqueiro, vendedor de sorvetes e agora era garçom, sempre trabalhando continuamente para ajudar sua familia, desde os nove anos fora um subversivo, um sujeito que nunca aceitou as coisas como elas lhe eram impostas; sempre fora um reacionário; estaria ele acima da lei por pensar e agir diferentemente dos outros? (...) A partir daquele dia soube que ele era um comunista. Mas, sor- 
rindo, se prometeu que nunca comeria criancinhas (PRADO, 2013, p.45).

Porém, o fato de servir bebidas para os integrantes do Grupo dos Onze e, não raras vezes, escutar conversas indevidas que mal compreendia o significado, custou caro ao menino garçom, pois ele foi seqüestrado e torturado por algozes da ditadura, os quais acreditavam que ele tinha informações importantes acerca dos subversivos.

\section{Conceito de História em Mácula}

Martin Heidegger, em Ser e tempo (2002), discorre sobre o conceito dialético de história, na medida em que esta compreende ascensões e quedas:

O que tem história encontra-se inserido num devir. O seu desenvolvimento pode ser ora ascensão, ora queda. O que, desse modo, tem uma história, pode, ao mesmo tempo, fazer história. É fazendo época que, no presente, se determina um futuro. História significa, aqui, um "conjunto de acontecimentos e influências que atravessa passado, presente e futuro". Aqui, o passado não tem primazia (HEIDEGGER, 2002, p. 184).

A ênfase da teoria de Heidegger (2002) sobre a história está no legado que continua influenciando as convivências, pois a história é o acontecer específico da presença e esta permanece aberta no tempo, na medida em que o ser atravessa o limite que lhe é concedido entre passado e futuro. A seqüência de agoras que se agrupam para formar o que denominamos tempo é ininterrupta e a aporia, conforme Heidegger, só pode ser resolvida quando nos orientamos ontologicamente por um ser.

No enredo de Mácula (2013), o menino, ao recordar os momentos terríveis em que fora torturado, insere -se no pretérito com todo o legado histórico que herdamos e se compara aos seres flagelados de outrora:
Sentia na pele a marca do ferrete com o qual, nos tempos de dantes, os escravos e criminosos eram assinados. Dolorosamente sentia dentro de seu peito a desonra e a vergonha de ter sido encarcerado numa cela sórdida sem ter tido nenhuma chance de se defender das acusações que pensem sobre ele (PRADO, 2013, p. 217).

Nessa mesma linha, Paul Ricoeur, em A memória, a história e o esquecimento (2007), afirma que a História é um confronto entre o não-mais e o tendo-sido:

O discurso histórico deve ser construido em forma de obra; cada obra se insere num ambiente já edificado; as releituras do passado são outras tantas reconstruções, às vezes ao preço de custosas demolições: construir, desconstruir, reconstruir são gestos familiares para o historiador (RICOUER, 2007, p. 222).

Uma vez que a história se concretiza pelas atualizações das lembranças que são modificadas pelo esquecimento, quando determinadas recordações são traumáticas, o tempo fica estagnado. $\mathrm{O}$ futuro avança quando se vence o trauma e o já-foi se transforma em um tendo -sido não mais doloroso de ser rememorado.

O protagonista de Mácula afirma ter vencido o trauma muitas décadas depois, as rememorações enfermas assombraram-no de forma contundente, pois além de ter sido ameaçado de perder a vida caso contasse a alguém o que sofrera, também receiou que seu pai fosse massacrado por isso:

Este relato foi levado ao fogo brando e cozido bem devagar, durante décadas, fazendo parte da obscura história daquele garoto que acabou, sem planejar, se tornando um aprendiz de terrorista e subversivo, sob a ótica dos inquisidores. É levado a público somente agora, quarenta e sete anos depois do início da ditadura militar, quando não há mais o risco de que o pai do guri seja incriminado em um inquérito militar por desobediência civil e acabe sendo preso em uma caserna qualquer, deixando a família à mercê de ajuda alheia. Ou que o garoto também seja implicado sob a acusação de usar como arma letal um sapato de biqueira 
de chapa de ferro (PRADO, 2013, p.349).

Conforme Freud (1996), todos os cursos tomados pelos eventos mentais são com a finalidade de produzir prazer. Nessa medida, são traumáticos quaisquer estímulos provindos de fora que sejam suficientemente poderosos para atravessar o escudo protetor:

Um acontecimento como um trauma externo está destinado a provocar um distúrbio em grande escala no funcionamento da energia do organismo e a colocar em movimento todas as medidas defensivas possíveis. Ao mesmo tempo, o princípio de prazer é momentaneamente posto fora de ação (FREUD, 1996, p.34).

O portador de uma lembrança traumática busca evitar o desprazer que seria produzido pela liberação do reprimido, desviando sua atenção para outro foco e, assim, as lembranças se imbricam com a tentativa de esquecimento e com distintas recordações, formando novos potenciais mnemônicos.

Além disso, liberar e relatar as rememorações enfermas é imprescindível para a repercussão da história dos vencidos. Cada relato de cada indivíduo que se envolveu direta ou indiretamente com a repressão da Ditadura Militar Brasileira é importante para a reconstituição da Memória Cultural desse capítulo horrendo da História Brasileira e Mundial. Não devemos jamais esquecê-lo, na medida em que somos todos herdeiros da dor sofrido e das privações que muitos tiveram.

De acordo com Regina Dalcastagné (1996):

Se ainda não podemos fazer alguma coisa, temos ao menos a obrigação de não esquecer. Em 21 anos de ditadura foram tantos os mortos, os torturados e os humilhados que faltaria espaço onde refugiar toda a sua dor. A memória, terreno tão propício, é demasiadamente instável para semelhantes horrores.

No Brasil foram os escritores que entalharam esse espaço acolhedor. É nos romances que vamos reencontrar, com maior intensidade, o desespero daqueles que foram massacrados por acreditarem que podiam fazer alguma coisa pela história do país (DALCASTAGNÈ, 1996, p. 1996).

Os algozes da ditadura tentaram, de distintas formas, anular as memórias dos que sofreram, como fica evidente, por exemplo, no enredo de Mácula, bem como tentaram incutir o trauma e o medo em suas vítimas:

Estaria sendo observado durante todas as horas do dia... essa premissa o acompanharia por anos a fio. Cada sombra que desaparecia ou surgia numa esquina, cada vulto surgido das sombras, cada cidadão estranho que brotava a sua frente, era motivo para um sobressalto (PRADO, 2013. p.331).

Todas as hesitações ao relatar um acontecimento traumático, todos os esquecimentos que se imbricam às recordações fazem parte de nossa Memória Cultural. Jan Assmann, em Religión y memoria cultural (2008), para desenvolver o conceito de memória cultural, usa o amálgama entre a base neuronal e social da memória, a saber:

Como la conciencia, el lenguaje y la personalidad, la memoria es un fenómeno social, y en la medida en que recordamos, no sólo descendemos a las profundidades de nuestra vida interior más propia, sino que introducimos en dicha vida un orden y una estructura que están socialmente condicionados y que nos ligan al mundo social (ASSMANN, 2008, p.18).

Por isso, é quase impossível distinguir entre memória individual e memória social, posto que aquela apenas se concretiza quando um indivíduo age em sociedade. Assmann (2008) cunha o termo memória comunicativa para demonstrar o aspecto social da memória individual: "No es sólo que la socialización nos permite recordar, sino también al revés, nuestros recuerdos nos permiten socializarnos" (ASSMANN, 2008, p.21). 
A memória coletiva, por sua vez, tem como propósito a transmissão de uma identidade coletiva, ou seja, é uma forma de consciência moral na medida em que a sociedade se inscreve nessa memória com suas normas e valores, estando sujeita às formas politizadas de recordação: "Es una cuestión del colectivo social, que quiere recordar, y también del individuo, que recuerda para pertenecer a él” (ASSMANN, 2008, p.24). E a memória cultural abarca o resultado da interação entre psique, consciência, sociedade e cultura:

En contraste con la memoria comunicati$v a$, la cultural abarca lo originário, lo excluido, lo descartado, y en contraste con la memoria vinculante y colectiva, abarca lo no instrumentalizable, lo herético, lo subversivo, lo separado. Con el concepto de memoria cultural, alcanzamos el confín más remoto de nuestro punto de partida: la memoria individual en sus condiciones neuronales e sociales (ASSMANN, 2008, p.47).

Ao contrário da memória coletiva, que dita preceitos para os que nela querem se incluir, a memória cultural é labiríntica e pluralista porque compreende inúmeras identidades distintas e, a partir dessas tensões e contradições, extrai uma dinâmica própria. A memória cultural pode ser entendida como a soma das formas nas quais um mundo simbólico de sentido é possível de ser comunicado e transferido: "Junto con una cierta visión del mundo, la memoria cultural expande y reproduce una conciencia mundial de unidad, particularidad e co-pertenencia entre los miembros de un grupo" (ASSMANN, 2008, p. 59).

Para a análise e compreensão da Memória Cultural, é mister levar em consideração as diversas vozes de diferentes narrativas. No romance Mácula, por exemplo, temos a voz do garoto narrador, que não compreendia a dimensão histórica e política dos acontecimentos, temos as vozes dos amigos do bar, que eram subversivos, e as vozes dos militares, cujos discursos profetizavam o bem que eles faziam à Nação Brasileira e o mal que os comunistas incutiam na sociedade. Podemos perceber a visão de mundo do algoz que capturou o menino de Mácula, o qual responde ao garoto após este afirmar que seus amigos do bar eram trabalhadores, e não terroristas:

Eles te fizeram uma lavagem cerebral, piá de bosta! Aqueles caras formam um bando de comunistas sujos que só querem transformar nosso país num caos igual à maldita Cuba ou à União Soviética ou à China (PRADO, 2013, p.308).

Ademais, as vozes dos que foram exilados por serem contra o Regime Militar, também fazem parte da Memória Cultural, bem como seus esquecimentos e traumas se juntam, a cada instante, no vir-a-ser temporal.

Um dos amigos do garoto de Mácula, que sobreviveu às torturas, contribuiu para a narrativa:

Viajou para o Chile... quem sabe nas terras de Allende consiga um pouco de paz... afirmou-me no entanto que não perdeu a fé nos seus ideais, apesar de ter ainda os olhos roxos e costelas quebradas no dia em que o vi... - Falou-me que tem pesadelos todas as noites desde que foi solto pela Ditadura (PRADO, 2013, p.272).

\section{Mácula: Arte engajada}

Acerca do conceito de literatura, Jean-Paul Sartre, afirma “(...) a função do escritor é fazer com que ninguém possa ignorar o mundo e considerar-se inocente diante dele (2004, p.21). O filósofo acredita em arte engajada e no fato de que as personagens devem desvendar o mundo ao leitor, ajudando-o a enxergar suas possibilidades.

Outro fator que chama atenção em Sartre é sua noção de liberdade. Jean-Paul Sartre declara:

Assim, quer seja ensaista, panfletária, satirista ou romancista, quer fale somente das paixões individuais ou se lance contra o regime social, o escritor, homem 
livre que se dirige a homens livres, tem apenas o único tema: a liberdade (SARTRE, 2004, p.52).

Sartre discorre sobre o engajamento da arte literária e sua relação necessária com a liberdade, temas correlatos aparecem na filosofia do absurdo de Albert Camus, que afirma:

Aceitar todo o processo histórico seria aceitar o mal em nome de um bem futuro, a realização da totalidade. Mas o revoltado não pode aceitar a justificação do mal, e a lógica da história, no momento em que ela é aceita incondicionalmente, leva pouco a pouco a mutilar o homem (CAMUS, 1942, p.30).

Camus, em sua novela intitulada $A$ Peste, relata o infortúnio da cidade chamada Oran, a qual foi acometida por uma peste transmitida por ratos, o que lhe serve de pretexto para analisar os conceitos de liberdade e de arte engajada, como vemos na declaração do narrador acerca das pessoas que permaneciam imunes à enfermidade: "Julgavam-se livres, e nunca alguém será livre enquanto houver flagelos (CAMUS, p. 24).
Dessa forma, o romance Mácula, de Pedro Penteado do Prado (2013), cumpre sua função de ser arte engajada, de iluminar o leitor acerca de uma época histórica incomensuravelmente importante por continuar nos determinando como sujeitos históricos. E sabemos que, apesar de todo sofrimento dos que, alhures, lutaram pela liberdade, ainda não somos livres, ainda há muito o que fazermos. É notório que há inúmeros indivíduos que ainda não curaram seus traumas e que, ao contrário de Pedro Penteado do Prado, que conseguiu transformar seu sofrimento em obra de arte, continuam sufocados por lembranças enfermas.

E a nossa função, enquanto leitores, é, no mínimo, não esquecer desse capítulo de nossa História. Ler, analisar e valorizar os relatos orais e escritos dos que se envolveram na Ditadura, dos que viveram na época de chumbo, principalmente narrativas novas de pessoas que venceram seus traumas e conseguiram compartilhar suas experiências e, dessa forma, enriquecer nossa Memória Cultural e continuar nos ajudando em nossa ininterrupta determinação como sujeitos histórico-culturais. 


\section{Referências bibliográficas}

ASSMANN, Jan. Religión y memoria cultural: Diez estudios. Buenos Aires: Limod, Libros de la Araucaria, 2008. CAMUS, Albert. A peste. In: lelivros.net. Acesso em janeiro de 2016. . El hombre rebelde. Buenos Aires: Editora Losada, 1955.

DALCASTAGNÈ, Regina. O espaço da dor. O regime de 64 no romance brasileiro. Brasília: Editora Universidade de Brasília, 1996.

FREUD, Sigmund. Além do princípio do prazer. In: . Obras psicológicas completas. Rio de Janeiro: Imago, 1996.

HEIDEGGER, Martin. Ser e tempo. 11 ed. Petrópolis: Vozes, 2002 Parte I.

PRADO, Pedro Penteado. Mácula. Canoinhas: Nova Letra Gráfica e Editora, 2013.

RICOUER, Paul. A memória, a história, o esquecimento. Trad. de Alain Français (et al). Campinas: Editora UNICAMP, 2007.

SARTRE, Jean Paul. Que é literatura? 3 ed. São Paulo: Ática, 2004.

Submissão: $18 / 02 / 2016$

Aceite: $26 / 07 / 2016$ 